\title{
Labuta, sociabilidade, solidariedade e conflito: mulheres pobres, trabalhadoras e negras em Feira de Santana, 1890-1920
}

\author{
Karine Teixeira Damasceno*
}

Resumo: A partir dos processos-crimes e recenseamentos populacionais no período entre 1890 e 1920, buscamos compreender a experiência de aproximação e de diferenciação entre as mulheres pobres, trabalhadoras e negras de Feira de Santana. Perguntamo-nos como essa experiência interferiu na sua relação com outros sujeitos sociais, e ao reconstituir alguns episódios vivenciados por tais mulheres observamos que, embora elas compartilhassem a experiência comum de opressão e, em muitos casos, se comportassem de maneiras semelhantes ao escolher a mesma estratégia de autorrepresentação diante da Justiça, por diversas vezes encontravam saídas diferentes para resolver seus problemas. Nesse sentido, descortinar o passado dessas personagens trouxe à tona seus valores e os vários momentos de luta pela sobrevivência, sociabilidade e solidariedade construídas por essas mulheres, assim como os conflitos nos quais, de alguma forma, elas estiveram envolvidas.

Palavras-chave: mulheres pobres; trabalhadoras; negras; Feira de Santana.

Abstract: From the crime processes and population census in the period between 1890 and 1920, we tried to understand the experience of approaching and differentiation between poor, working and black women from Feira de Santana. We asked ourselves how this experience interfered in their relation with other social people and in the reconstruction some episodes which were experienced by such women, we observe that, though they share the same experience of oppresion, and in most of the cases, they behave in the same way to choose the same self representation strategy to the justice, by several times they found different ways to solve their problems. In this sense, uncover the past of these characters brought to light their values and the several times of fight for survival,

* Doutoranda em História na Universidade Federal da Bahia (UFBA). As reflexões apresentadas neste texto fazem parte da pesquisa realizada para a escrita de minha dissertação de mestrado apresentada ao Departamento de História do Instituto de Filosofia e Ciências Humanas da Universidade Estadual de Campinas (Unicamp) em 2011. 
sociability and solidarity built by these women as well as the conflicts which, in anyway, they were involved.

Keywords: poor women; working women; black women; Feira de Santana.

De maneira geral, as mulheres pobres trabalhadoras e negras de Feira de Santana, entre 1890 e 1920, eram alvo principal do olhar repressivo das autoridades locais. Suas práticas, seus valores e seu modo de vida, inevitavelmente, transformavam-nas em transgressoras do padrão de feminilidade que a elite considerava adequado para todas as mulheres, isto é, pretendia-se que fossem passivas, submissas e apenas dedicadas às coisas do lar. No entanto, embora tenhamos notado vários aspectos comuns entre elas, ignorar as singularidades desse grupo social significa correr o risco de homogeneizar e simplificar suas experiências. Por isso, neste texto, nosso objetivo principal é compreender a experiência de aproximação e diferenciação entre as mulheres pobres, trabalhadoras e negras, e como tal experiência interferia na relação com outros sujeitos sociais.

A opressão constituiu um aspecto comum que aproximava todas as mulheres cujos fragmentos de suas vidas buscamos reconstituir neste estudo. Por outro lado, nem todas elas viviam essa experiência comum do mesmo modo e, ao mesmo tempo, nem todas as mulheres pobres eram negras ou trabalhadoras e vice-versa. Assim, ao esmiuçar o cotidiano dessas mulheres, podemos observar que, ao longo de suas vidas, as semelhanças e as diferenças podiam assumir combinações variadas. Uma mulher podia identificar-se com outra numa determinada situação e diferenciar-se dela em outra.

Desse modo, a despeito dos momentos de conflitos buscamos destacar a ampla rede de sociabilidade e solidariedade em que nossas protagonistas estavam inseridas e que, por sua vez, era fundamental para a sobrevivência. A relação dessas mulheres com outros grupos sociais - homens pobres (ex-companheiros, companheiros e conhecidos) e juristas - também assumia formatos variados: por vezes, elas eram vistas e tratadas sem distinção e, por outras, de forma diferenciada; e elas não eram ingênuas quanto a isso.

\section{Duas mulheres pobres e outros sujeitos sociais}

Na noite do dia 7 de outubro de 1900, o comissário de polícia, major José Antônio Guimarães, recebeu, no quartel de Feira de Santana, Maria Leonidia Simplicia de Cerqueira, de 35 anos, casada e abandonada pelo marido, trabalhadora doméstica, analfabeta, natural e residente em Feira de Santana, mais especificamente no Beco da Esteira. ${ }^{1}$ Ela apresentava dois ferimentos no rosto e, ao prestar uma queixa, relatou que, por volta das oito horas da noite, ao voltar da fonte, preparou uma comida e convidou uma rapariga de nome Fenícia para jantar em sua casa; logo em seguida, chegou Maria Cocó e pôs-se a provocá-la. Informou ainda que, após o fim do jantar, resolveu ir até a venda de Marcellino de Tal, próxima a sua casa. Quando se dirigia até lá, percebeu que a acusada vinha ao

1 O Beco da Esteira ficava localizado na região onde hoje encontramos a Rua Dr. Olímpio Vital, como se verifica em: ALMEIDA, Oscar Damião de. Dicionário Personativo, histórico, geográfico e institucional Dicionário de Feira de Santana. Feira de Santana, Editora: Gráfica Nunes Azevedo, 2002, p. 156. 
seu encontro e, ao notar a intenção da outra, avisou logo que não queria brigar. Entretanto, Maria Cocó não se deteve e empurrou-a com força, ao ponto de levá-la ao chão. A vítima continuou relatando que, a partir daí, as duas entraram em luta, mas Porfírio de Tal interferiu no conflito, pegando em seu braço de modo a impedila de continuar o confronto, oportunidade aproveitada pela adversária para dar-lhe golpes de navalha. Segundo Maria Leonídia, elas eram amigas íntimas, tanto que, tempos atrás, Maria Cocó pôde contar com sua solidariedade, pois a ajudou nos cuidados com sua irmã doente. Segundo ela, provavelmente, o comportamento provocativo e agressivo da outra se devia à embriaguez.

Em 1 de março de 1901, o caso seguia na Justiça como Sumário Crime. Ao ser interrogada pelo juiz de Direito Francisco Souza Dias, Maria Francelina de Oliveira, conhecida por Maria Cocó, de 40 anos, filha de Carmélia de Tal, analfabeta, natural do distrito de Almas e moradora de Feira de Santana há mais de 20 anos, onde sobrevivia como proprietária de uma quitanda, negou a autoria do crime, declarando que, no momento do ocorrido, estava jantando em casa, localizada no Beco da Esteira. ${ }^{2}$

Ao serem inquiridas sobre o crime, as testemunhas foram unânimes ao informar que sabiam da amizade entre as duas mulheres. Venância de Paula de Cerqueira, de 19 anos, solteira, costureira, analfabeta, natural de São Vicente, distrito de Santa Bárbara, e residente em Feira de Santana, por exemplo, disse que, no dia e na hora a que se refere a denúncia, estava na porta de sua casa no Beco da Esteira quando ouviu uma troca de palavras entre a denunciada e a vítima e que, logo depois, as duas mulheres se agrediram fisicamente ao ponto de caírem no chão durante a luta, mas, diante de tão assustadora cena, sentiu medo e retirou-se para dentro de casa a fim de cuidar de seu filho, retornando à porta somente depois do fim da briga. Já Constança Maria de Jesus, de 25 anos, solteira, analfabeta, natural de Bom Despacho, também disse que é moradora do Beco da Esteira, mas estava na rua no momento da contenda entre as duas amigas, não assistindo ao ocorrido. Entretanto, soubera do caso por Maria Francisca dos Santos e Venância de Tal. Salientou ainda que todos os moradores do beco tomaram conhecimento de que a acusada fizera dois grandes ferimentos na vítima com uma navalha.

O episódio acima fornece elementos importantes sobre o cotidiano das mulheres pobres de Feira de Santana na virada do século XIX para o século XX. Por meio dele, podemos perceber as várias faces desse grupo social que transitava com facilidade entre o mundo privado e o público. ${ }^{3}$ Nesse sentido, as versões sobre o conflito tratado nos deixam ver que a vizinhança, a rua, a fonte, ${ }^{4}$ a venda, 5 a briga e a embriaguez faziam parte do mundo dessas mulheres, para as quais transgredir o lugar de subalternidade de gênero, raça e classe que lhes era

2 Tribunal de Apelação. A Justiça Pública (Autor), Maria Francillina de Oliveira, conhecida por Maria Cocó (Ré). Feira de Santana - CEDOC/UEFS. Seção Judiciária, Processos-crimes, 1900-1901. E. 01, Cx. 29, Doc. 515, fls. 27. v-28.v.

3 Para saber mais sobre o método heurístico - procedimento de investigação e análise dos indícios proposto por Carlo Ginzburg, o qual nos inspirou, verificar em: GINZBURB, Carlo. Mito, emblemas e sinais: morfologia e história. São Paulo: Companhia das Letras, 1989, p. 143-179.

4 Ao reconstituir o cotidiano do universo do trabalho de negras no Terreiro de Jesus, em 1871, especialmente o protesto organizado por africanas contra as exigências disciplinadoras que lhes eram impostas pela segurança da fonte, Vivaldo da Costa Lima desvenda as múltiplas funções sociais desse espaço de trabalhadores - ponto de encontro, de reunião, local de conversas, de projetos, de lazer e para descanso ("Um Boicote de Africanas na Bahia do século XIX". Revista da Bahia, Salvador, n. 15, p. 16-22, dez. 1989-fev. 1990.).

5 Segundo Josiane Thethê Andrade, a venda constituía um espaço de múltiplas funções, pois, mais do que um local de compra e venda de produtos, também era um espaço de sociabilidade, de solidariedade e palco de conflitos. ANDRADE, Thethê. "O tabuleiro das vendas: um cotidiano marcado pelas lojas das roças". (Dissertação de mestrado em História, Universidade do Estado da Bahia, 2010), p. 66. 
imposto pela sociedade constituía condição fundamental para a sobrevivência. ${ }^{6}$ Diferentemente da passividade esperada e admitida para as mulheres, aquelas aqui referenciadas precisavam ser autônomas e preparadas para resolver, sozinhas, seus próprios problemas. Além disso, elas integravam amplas redes de sociabilidade e solidariedade que, ao constituírem um mecanismo de aproximação indispensável para a garantia da sobrevivência, era tradicionalmente acionado por elas e pela população pobre em geral.

O acesso a fragmentos do passado dessas mulheres somente foi possível por meio do registro judicial nos quais elas apareceram como vítimas, rés ou testemunhas, documentação que nos deixa ver que elas conheciam muito bem as regras e os valores da sociedade feirense e, quando lhes era conveniente, usavamnos a seu favor; isto é, sabiam muito bem o que dizer à Justiça na hora de contar sua versão dos fatos.?

Maria Leonídia, por exemplo, não era ingênua quanto à diferença entre dizer que era separada e explicar que fora abandonada pelo marido, pois, ao prestar a queixa contra Maria Cocó, ela se colocou na posição de vítima do conflito. Sabia que o caso não seria julgado apenas pelo fato denunciado, mas também que sua postura de mulher honesta seria posta em xeque. Nesse caso, ela construiu um discurso que a aproximasse, ao máximo, do papel socialmente admitido para as mulheres, ou seja, ela se autorrepresentou como mulher casada e submissa, o que significa que ela não escolhera se separar do marido, mas sim fora vítima de abandono. No entanto, ainda considerando possível que ela, de fato, tivesse sido abandonada ou que se sentisse dessa maneira, certamente não foi por acaso que ela lançou mão dessa informação ao procurar a Justiça. Assim, ao traçar um perfil aproximando-se de determinado modelo de feminilidade, ela também demonstrou conhecer a noção diferenciadora que a Justiça adotava para identificar as mulheres desviantes das normas; isto é, sendo que algumas delas eram tidas como insubmissas às regras de conduta social e jurídicas por, inclusive, escolher separar-se do marido, era estratégico para Leonídia explicar que tinha um bom procedimento, uma vez que precisava convencer a Justiça sobre sua posição de vítima no conflito.

Da mesma forma, Venância de Tal, jovem mãe solteira, conhecia a importância de dizer que não tinha visto o exato momento do crime por medo da violência e, ao mesmo tempo, explicitar que era diferente das mulheres que, como as acusadas, se envolviam em brigas. Ainda reforçou a negativa, dizendo ter entrado em casa para cuidar do filho pequeno. No entanto, o fato de ser mãe solteira, aliás, condição similar a de outras tantas mulheres pesquisadas, já depunha contra sua

6 Para ter acesso aos conceitos de gênero, raça e classe utilizados para a realização deste estudo consultar, cf. CUNHA, Maria Clementina Pereira. "De historiadora, brasileiras e escandinavas: loucura, folias e relações de gênero no Brasil (século XIX e início do século XX)". Tempo, Rio de Janeiro, v. 3, n. 5, p. 181-215, 1998; GUIMARÃES, Antonio Sérgio Alfredo. Classes, raças e democracia. São Paulo: Editora 34, 2002, p. 47-77; SCOTT, Joan Wallach. "Prefácio a gender and politics of history". Cadernos Pagu, Campinas, n. 3, p. 11-27, 1994; SCOTT, Joan. "Gênero: uma categoria útil para a análise histórica”. Disponível em: http://www. dhnet.org.br/direitos/textos/generodh/gen_categoria.html. Acesso em: 4 abr. 2011. Ver também: SCOTT, Joan. "História das mulheres". In: BURKE, Peter (Org.). A escrita da história: novas perspectivas. São Paulo: UNESP, 1992, p. 63-95 e THOMPSON, Edward Palmer. A formação da classe operária inglesa, v. I: a árvore da

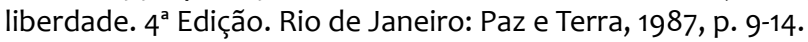

7 Para ter acesso a uma reflexão interessante sobre a importância dos processos judiciais enquanto fonte de pesquisa histórica, cf. CAULFIELD, Sueann. "Raça, sexo e casamento: crimes sexuais no Rio de Janeiro, 1918-1940". Afro-Ásia, Salvador, n. 18, p. 125-164, 1996; CAULFIELD, Sueann. Em defesa da honra: moralidade, modernidade e nação no Rio de Janeiro, 1918-1940. Campinas: UNICAMP, 2000, p. 205 e CHALHOUB, Sidney. Trabalho, lar e botequim: o cotidiano dos trabalhadores no Rio de Janeiro da Belle Époque. $2^{\mathrm{a}}$ Ed. Campinas: Editora da Unicamp, 2001, p. 41. 
honra aos olhos das autoridades; mesmo assim, Venância lançou mão de outros atributos admitidos para as mulheres: o de mulher pacífica e de mãe zelosa, sendo que o segundo a colocou em contradição, pois ela, que provavelmente fora vista por outras pessoas no momento da contenda, teve que admitir que testemunhara pelo menos uma parte do conflito, ou seja, que, no mínimo, dividira sua atenção entre o filho e os acontecimentos do beco. Ademais, é importante observar que estamos tratando aqui de mulheres pobres que, como muitas que encontramos ao longo da pesquisa, eram chefes de família e, fossem elas solteiras, casadas, amasiadas, abandonadas, filhas ou mães, precisavam trabalhar para garantir a própria sobrevivência e a dos seus; mulheres cuja condição social Ihes impunha como experiência comum a incômoda posição de alvo preferencial da Justiça. Desse modo, na maior parte das vezes, elas se comportavam de maneiras semelhantes ao escolher a mesma estratégia de autorrepresentação diante das autoridades judiciais: passivas, submissas e dedicadas às coisas do lar, modelo referenciado pela sociedade feirense.

Apesar de Maria Leonídia não especificar qual atividade doméstica exercia, sabemos que ela frequentava a fonte e certamente se relacionava com outras mulheres pobres, que, assim como ela, lavavam roupa no local, além dos outros inúmeros trabalhadores que frequentavam ou passavam pela fonte, como os vaqueiros que vinham de vários lugares do sertão rumo a Salvador. ${ }^{8}$

Embora Feira de Santana fosse uma cidade com a economia voltada para o comércio e para a agropecuária, os 30 processos analisados revelam ainda que, depois da agricultura, a atividade mais comum entre as mulheres era o trabalho como doméstica. ${ }^{9}$ A pesquisa realizada por Fraga Filho ainda nos ajuda a pensar o exercício de determinadas ocupações em Feira de Santana, já que, segundo ele, o trabalho doméstico, que tradicionalmente era exercido pelas mulheres negras, continuava sendo a ocupação mais comum entre as libertas, tanto que chegavam a representar $93,8 \%$, dos trabalhadores nesse setor. Para esse autor, na região do Recôncavo baiano, além da resistência das mulheres brancas pobres em trabalhar como domésticas, os patrões, "amas" e "amos", também preferiam contratar mulheres negras para realizar trabalhos como o de "ama-seca", engomadeira, cozinheira, costureira e lavadeira. ${ }^{10}$

8 Sobre Feira de Santana enquanto local obrigatório de passagem, cf. ANDRADE, Celeste Maria Pacheco de. "Origens do povoamento de Feira de Santana: um estudo de história colonial" (Dissertação de mestrado em História, Universidade Federal da Bahia, 1990); FREIRE, Luiz Cleber Moraes. "Nem tanto ao mar, nem tanto à terra: agropecuária, escravidão e riqueza em Feira de Santana, 1850-1888" (Dissertação de mestrado em História, Universidade Federal da Bahia, 2007); POPPINO, Rollie E. Feira de Santana; OLIVEIRA, Ana Maria Carvalho dos Santos. "Feira de Santana em Tempos de Modernidade: olhares, imagens e práticas do cotidiano (1950-1960)" (Tese de doutorado em História, Universidade Federal de Pernambuco, 2008) e OLIVEIRA, Clóvis Frederico Ramaiana Moraes. "De empório a Princesa do Sertão: utopias civilizadoras em Feira de Santana (1893-1937)" (Dissertação de mestrado em História, Universidade Federal da Bahia, 2000).

9 Na pesquisa realizada em um universo de 260 pessoas, recortando os dados por sexo, verificamos que 29 mulheres (37,7\% delas) e 122 homens ( $66,7 \%$ deles) declararam garantir sua sobrevivência trabalhando na lavoura. Também nesse universo específico, a segunda atividade mais comum entre as mulheres era o trabalho doméstico, exercido por 15 delas $(20,8 \%)$ e, entre os homens, o trabalho de negociante, que envolvia 19 deles (10,4\%). Verificar os dados acima em: DAMASCENO, Karine Teixeira. "Mal ou bem procedidas: cotidiano de transgressão das regras sociais e jurídicas em Feira de Santana, 1890-1920" (Dissertação de mestrado em História, Universidade Estadual de Campinas, 2011), p. 53-54. Para ver outras abordagens sobre trabalhadoras domésticas consultar: ESTEVES, Martha de Abreu. Meninas perdidas: os populares e o cotidiano do amor no Rio de Janeiro da Belle Époque. Rio de Janeiro: Paz e Terra, 1989; SILVA, Maciel Henrique. Nem mãe preta, nem negra fulô: história de trabalhadoras em Recife e Salvador (1870-1910). Jundiaí: Paco Editorial, 2016 e SOUZA, Flavia Fernandes de. "Escravas do lar: as mulheres negras e o trabalho doméstico na corte imperial". In: XAVIER, Giovana; FARIAS, Juliana Barreto; GOMES, Flavia (Orgs.). Mulheres negras no Brasil escravista e do pós-emancipação. São Paulo: Selo Negro, 2012.

10 FRAGA FILHO, W. "Migrações, itinerários e esperanças de mobilidade social no Recôncavo baiano após 
Nesse sentido, ao tratar das escolhas dos libertos e de suas filhas e netas, Hebe Matos observa que, nas Américas, no período do pós-emancipação, canalizar o trabalho das mulheres e das crianças para o âmbito doméstico e de subsistência fez parte do projeto dessas famílias, resultando numa retirada progressiva desses trabalhadores da lavoura. ${ }^{11}$ Desse modo, a despeito de termos encontrado uma porcentagem significativa de mulheres negras dedicadas ao trabalho rural, tal observação colabora para a nossa reflexão sobre o significado do agenciamento dessas mulheres sobre suas próprias vidas em Feira de Santana, já que, dentre as poucas possibilidades de escolhas ocupacionais para elas, o trabalho doméstico apresentava-se como uma alternativa importante de sobrevivência adotada, embora sua presença no trabalho agrícola e na indústria predominasse.

Dentre as mulheres envolvidas no episódio acima, apenas Maria Cocó afirmou trabalhar diretamente com o comércio, pois tinha uma quitanda que administrava sozinha, tarefa que a colocava em contato diário com uma clientela bastante diversificada, principalmente nos dias de feira quando a cidade recebia várias pessoas de outros lugares para negociar. Assim, as mulheres tratadas tinham como experiência comum a condição de trabalhadoras. Ao mesmo tempo, diferenciavam-se umas das outras ao exercerem ocupações diversas (lavadeiras, costureiras e quitandeiras), que lhes possibilitavam graus de autonomia, mobilidade e prestígio social em níveis variados.

O Beco da Esteira, local onde aconteceu o conflito entre as duas amigas, nos diz muito sobre o universo dessas mulheres, visto que se trata de uma área bastante movimentada, próxima ao coração comercial da cidade, a Praça João Pedreira, onde acontecia a grande feira semanal de Feira de Santana.

Conforme pudemos constatar das falas das mulheres ouvidas pela Justiça, seu universo de relações extrapolava o âmbito familiar, já que incluía a vizinhança, colegas de trabalho, clientes, patrões, fregueses e também as pessoas que transitavam pelo beco. Essa extensa rede de relações ajudava a compor o mundo dessas mulheres, que, assim como outros grupos sociais, imprimiam seu jeito de vivenciá-lo à dinâmica da cidade. Por isso mesmo, para que possamos entender melhor as histórias de Maria Leonídia, Maria Cocó e das outras mulheres que testemunharam nesses processos, bem como as nuanças das diferentes narrativas apresentadas por elas, é preciso levar em conta que suas vidas estavam intrinsecamente ligadas à de outros personagens e aos lugares sociais ocupados por estes em Feira de Santana.

\section{Prática de luta pela sobrevivência em família}

Ao avançarmos na análise dos processos em busca do passado das mulheres pobres, trabalhadoras e negras de Feira de Santana, vários sujeitos próximos a elas se mostraram importantes para nossa investigação. Assim, bastou puxar um fio para ouvirmos o choro alto de suas filhas e filhos pequenos, o chamado ou lamento de suas mães e pais e, por vezes, as querelas entre casais. Eis alguns desses sons.

a abolição". Cadernos AEL, Campinas, n. 26, v. 14, 2009, p. 124. Consultar ainda: MACHADO, Maria Helena Toledo. "Entre dois Beneditos: histórias de amas de leite no caso da escravidão". In: XAVIER, Giovana; FARIAS, Juliana Barreto; GOMES, Flavia (Orgs.). Mulheres negras no Brasil escravista e do pós-emancipação. São Paulo: Selo Negro, 2012, p. 199-213.

11 MATTOS, Hebe Maria; RIOS, Ana Lugão. Memórias do cativeiro: família, trabalho e cidadania no pósabolição. Rio de Janeiro: Civilização Brasileira, 2005, p. 169. 
Em 27 de fevereiro de 1908, Maria Simplícia Bernarda do Espírito Santo, de mais ou menos 40 anos, filha de Bernardina de Tal, viúva, lavradora, analfabeta, natural de um lugar denominado Caatinga, e sua filha Maria Gregória, de mais ou menos 22 anos, solteira, lavradora, analfabeta, ambas moradoras da localidade de São José, foram até o quartel da cidade de Feira de Santana afirmando terem sido vítimas de agressão física e prestaram uma queixa contra Maria Martina. A partir do depoimento de Maria Simplícia, podemos depreender que a tensão entre as famílias havia se originado num contexto de luta pela sobrevivência, já que, segundo a queixosa, em julho do ano anterior, três animais pertencentes a Basílio de Almeida tinham entrado em sua roça

[...] e fizeram bastante estrago. Então, mandou dizer ao mesmo Basílio de Almeida que colocasse um chocalho em um burro que fazia parte dos animais acima e em resposta obteve o seguinte: o chocalho que eu tinha já botei no cavalo, só se ela perguntada mandar o seu chocalho; sendo ela perguntada prejudicada em sua lavoura e não obtendo por meio brando do referido Basílio de Almeida retirar os animais da roça dela, a perguntada [ilegível] a enxotar a pau os referidos animais de dentro da sua roça, ficando muito contrariada a mulher de Basílio de Almeida, e prometeu depois de muita ameaça se vingar dela perguntada e sua filha Maria Gregória [ilegível]. No fim de julho do ano passado, indo a filha dela perguntada Maria Gregória buscar água em uma fonte que fica próxima à morada dela perguntada, e sendo de sua propriedade a mesma fonte, foi sua filha Maria Gregória surpreendida por Maria Martina, mulher de Basílio de Almeida, que armada de pau vibrou uma cacetada na cabeça de Maria Gregória e agarrando esta a jogou dentro da fonte de cabeça para baixo, salvando a mesma Maria Gregória de não morrer afogada algumas mulheres que se achavam na ocasião na referida fonte, voltando Maria Gregória para casa e pedindo que ela perguntada a socorresse: inocentemente ela perguntada saiu armada com um pau em direção à fonte a procurar o algoz de sua filha e de fato encontrou na mesma fonte Maria Martina mulher de Basílio de Almeida e travaram-se em rasgões resultando saírem ambas com pequenos arranhões $[. . .]^{12}$.

O depoimento de Maria Simplícia possibilita a compreensão de que se tratava de uma família constituída apenas por mulheres e que elas possuíam uma pequena propriedade rural de onde tiravam seu próprio sustento. Além disso, revela tratar-se de mulheres autônomas, especialmente para resolver os problemas relacionados à sobrevivência, haja vista o conflito com a família de Maria Martina e Basílio, que, possivelmente, também possuíam uma pequena propriedade na qual criavam alguns animais, como as cabras citadas. $O$ caso ainda nos permite observar que as três mulheres envolvidas tinham um perfil similar, pois estavam longe da passividade feminina socialmente esperada; diferentemente disso, chegavam a optar pela violência para resolver seus problemas, sendo que duas delas ainda demonstraram estarem dispostas a resolver o conflito diante da Justiça. Nesse sentido, além de confirmar a versão da mãe, Maria Gregória ainda acrescentou que, depois desse ocorrido, ela e sua mãe foram buscar água na referida fonte e, inesperadamente, foram atacadas com um facão e cacete pelo casal e mais um neto deste, chamado Olavo. Ela ainda salientou que, antes desse episódio, já havia uma rixa entre sua mãe e a família supracitada.

Ao finalizar seu depoimento, Gregória informou que estava "grávida" e, devido às pancadas que recebera, sentia "dores e em virtude do seu mal estar",

12 Sumário Crime. A Justiça por seu Promotor (Autor), Maria Martira (Ré). Feira de Santana - CEDOC/UEFS. Seção Judiciária, Processos-crimes, 1908. E. 02, Cx. 44, Doc. 741. fls. 7-8.v. 
temia que a consequência da agressão fosse a "morte de seu filho". ${ }^{3}$ Ou seja, com tal informação, Maria Gregória revela outro dado importante sobre sua vida: ela seria mãe solteira, provavelmente, pois nenhuma testemunha ou ela mesma fez qualquer referência sobre a existência de um amásio ou de relacionamentos eventuais. Essas informações nos permitem supor que, para essas personagens, outros elementos, como o fato de se relacionarem bem com a vizinhança, serem trabalhadoras e garantirem o próprio sustento realizando o pesado trabalho de lavradoras, eram considerados tão emblemáticos da respeitabilidade da mãe e da filha que tornavam desnecessários quaisquer comentários sobre a honestidade de qualquer uma delas ou, no mínimo, elas puderam contar com a solidariedade dessas pessoas que diante da Justiça também preferiram não mencionar a situação sexo-afetiva de ambas. Ademais, semelhante a outras mulheres encontradas, Maria Simplícia e Maria Gregória vivenciavam um modelo de família muito comum entre os pobres tanto de Feira de Santana quanto de outras regiões do Brasil no período, isto é, famílias chefiadas por mulheres sós. ${ }^{14}$

Por meio de outro caso, acontecido um ano antes do mencionado acima, conseguimos recuperar alguns fragmentos da vida de outra família chefiada por uma mulher. As testemunhas chamadas para depor no inquérito policial sobre a morte de Maria Izabel Portugal informaram que ela residia com uma filha chamada Elane e um filho de nome Antônio Amâncio, no distrito de Humildes, e trabalhava fazendo farinha. Os depoimentos das testemunhas, lavradores e moradores do mesmo distrito, foram coincidentes. Eles ouviram da própria vítima ou de outras pessoas que ela havia se queixado de dor de dente e pretendia tomar cachaça com o objetivo de aliviar tal incômodo.

Em seu depoimento, Antônio Francisco Moreira afirmou que, ao visitar Maria Izabel, ouviu da própria "que estando com dor de dente, disse a seu filho que comprasse cânfora, para deitar na aguardente, e sulimão (veneno) para as formigas; e tendo os dois papéis vindos juntos, ela em vez de deitar a cânfora na aguardente, enganou-se e deitou o sulimão". ${ }^{15}$ Os depoimentos ainda foram reveladores de que Maria Izabel, preferencialmente tratada por senhora pelos depoentes, era bastante estimada e querida por todos no local e que ali "muito pertinho" moravam duas irmãs da falecida. ${ }^{16}$ Dadas as condições de pobreza e a responsabilidade de trabalhadora, mãe e chefe de família, certamente, em diversos momentos da vida, Maria Izabel, que certamente estava inserida numa ampla rede de sociabilidade, precisou contar tanto com a solidariedade da vizinhança quanto com a de familiares, como as irmãs citadas acima.

13 Sumário Crime. A Justiça por seu Promotor (Autor), Maria Martira (Ré). Feira de Santana - CEDOC/UEFS. Seção Judiciária, Processos-crimes, 1908. E. 02, Cx. 44, Doc. 741, fls. 9-9.v.

14 Ver: DIAS, Maria Odila Leite da Silva. Quotidiano e poder: em São Paulo no século XIX. São Paulo: Brasiliense. 1995, p. 175-212. Observando São Paulo no contexto do século XIX, essa autora contribui para nosso estudo ao informar que as famílias matrifocais eram muito comuns, assim como, a existência de dependentes adultos, principalmente filhas, sendo que a unidade do grupo e a relação de solidariedade construída com a vizinhança eram atreladas à autoridade da mais velha, ou seja, mãe ou avó. Dias ainda encontrou várias famílias como a chefiada por Maria Simplicia, nas quais as filhas e, eventualmente, netos trabalhavam para auxiliar na renda familiar. Consultar também: COSTA, Gomes Valéria. "Mônica da Costa e Teresa de Jesus: africanas libertas, status e rede sociais no Recife oitocentista". In: XAVIER, Giovana; FARIAS, Juliana Barreto; GOMES, Flavia (Orgs.). Mulheres negras no Brasil escravista e do pós-emancipação. São Paulo: Selo Negro, 2012, p. 98-111.

15 Inquérito Policial sobre a morte de Maria Izabel Portugal. Feira de Santana - CEDOC/UEFS. Seção Judiciária, Processos-crimes, 1907. E. 04, Cx. 102, Doc. 2128, fls. 7.

16 Inquérito Policial sobre a morte de Maria Izabel Portugal. Feira de Santana - CEDOC/UEFS. Seção Judiciária, Processos-crimes, 1907. E. 04, Cx. 102, Doc. 2128, fls. 11-12. 
Outros processos nos permitem ver aspectos da vida em família de outras mulheres pobres e são elucidativos da prática de trabalho em família, especialmente entre pequenos proprietários e trabalhadores rurais. Em 12 de março de 1909, Maria Bernardina Francisca, de mais ou menos 48 anos, de cor preta, solteira, lavradora, analfabeta, natural e residente em Terra Dura, foi levada até o quartel de Feira de Santana e, ao encontrar o subdelegado de Polícia em exercício, Virgílio Ferreira de Caldas, prestou uma queixa contra Cirillo Teixeira de Carvalho, de 60 anos, solteiro, lavrador, natural e residente no distrito de Humildes. Segundo ela, na

[...] segunda-feira, ao oito do corrente mês, indo pisar umas manivas [mandiocas], e não podendo continuar por achar-se doente, deixou de pisar, chegando nesta ocasião o dono da casa Cirillo Teixeira de Carvalho mandando ela respondente continuar pisar as manivas, dizendo ela respondente que não podia continuar a pisar por achar-se doente, este dizendo que ela tinha manhas, apoderou-se de uma vara indo contra ela respondente lhe fazendo os ferimentos constantes do corpo de delito, saindo nesta ocasião ela respondente procurando quem lhe acudisse pedindo misericórdia chegando sua filha que pelo amor de Deus: meu pai não faça isto com minha mãe, e ele Cirillo dando com a vara sem querer atender, dizia: hoje te mato. ${ }^{17}$

Infelizmente não foi possível saber se o casal de "amásios" tinha propriedades, mas acreditamos ser provável que as manivas tenham sido plantadas por pelo menos um deles. Além do mais, considerando uma possível divisão de tarefas entre o casal, o processo nos permitiu saber que pisar as manivas era uma das tarefas realizadas por Maria Bernardina, e certamente não era a única.

Em 12 de janeiro de 1904, Maria do Espírito Santo, de aproximadamente 30 anos, casada e moradora em Terra Dura, distrito de São José, prestou uma queixa contra seu vizinho, Maurício Martins da Silva, finalmente levando ao conhecimento da Justiça um conflito antigo entre ele e a vítima. Embora não tivesse presenciado o momento da agressão, Jovino Desidério das Neves informou ter ouvido dizer que

[...] entrando uns porcos de Maurinho [ilegível] em uma roça de Maria do Espírito Santo, conhecida por Mariquinha, indo uma criança, de cerca de seis anos, mais ou menos, filho desta, tanger da roça, com um cachorrinho os referidos animais, o denunciado penetrando na dita roça e com um chicote castigara a dita criança e quando Maria do Espírito Santo, despertada pelos gritos do filho, ali aparecendo foi, bruscamente, recebida pelo denunciado, que enfurecido, lançando mão de um pedaço de uma das estacas da dita cerca, virara-lhe uma cacetada partindo-Ihe o braço direito. ${ }^{18}$

Antônio Florêncio Morais, outra testemunha do processo, informou que Maria era "uma senhora distinta, bem quista por todos os vizinhos, casada e deu-se esse fato, achando-se ausente seu marido pelo que andava em procura de meios para a subsistência e de sua família". ${ }^{19}$ Ao que parece, semelhante a outras mulheres pesquisadas, o cotidiano de Maria era preenchido por uma dupla jornada, já que cabia a ela cuidar de seu filho pequeno ao mesmo tempo em que tratava da roça da família,

17 Sumário Crime. A Justiça Pública por seu Promotor (Autor), Cyrillo Teixeira Carvalho (Réu). Feira de Santana - CEDOC/UEFS. Seção Judiciária, Processos-crimes, 1909. E. 02, CX. 51, Doc. 854, fls. 7-8.

18 Denúncia. A Justiça pública por seu Promotor (Autor), Maurício Martins da Silva (Réu). Feira de Santana CEDOC/UEFS. Seção Judiciária, Processos-crimes, 1904. E. 01, Cx. 26, Doc. 478, fls. 21. v.22.

19 Denúncia. A Justiça Pública por seu Promotor (Autor), Maurício Martins da Silva (Réu). Feira de Santana CEDOC/UEFS. Seção Judiciária, Processos-crimes, 1904. E. 01, Cx. 26, Doc. 478, fls. 22. v. 24. 
onde, provavelmente, plantavam produtos que eram usados tanto para consumo próprio quanto para serem vendidos na feira livre. Enquanto isso, seu marido tentava complementar a sobrevivência familiar realizando outros trabalhos fora de casa.

O depoimento dessa testemunha ainda nos deixa ver que, embora para ele, e também para as outras pessoas mencionadas neste estudo, o casamento oficial conferisse respeitabilidade, ao enumerar as qualidades da vítima, ele mencionou outros elementos que influenciavam a caracterização de Maria como uma senhora respeitável. O depoente valorizava o fato de ela ser uma mãe zelosa ou mesmo mostrar-se autônoma no enfrentamento de situações difíceis, como diante da falta de recursos ou da necessidade de defesa de seu filho. Com efeito, ao dar vazão a toda a sua agressividade, ela demonstrou que, quando preciso, também lançava mão da violência física e, evidenciando sua identificação com outras mulheres pesquisadas, também sabia brigar, seja para defender seus filhos, seja para defender o sustento da família. Assim, ao defender seus interesses diante da Justiça, tentaram justificar a transgressão dos papéis sociais que lhes eram impostos utilizando o mesmo discurso empregado pelas autoridades para oprimilas: alegaram que estavam exercendo seu principal papel como mulher, o de mãe zelosa, e, por isso mesmo, foram capazes de usar da violência para defender seus filhos da agressão de terceiros. ${ }^{20}$ Entretanto, encontramos casos nos quais as mulheres demonstraram que poderiam ter outras motivações para que, em um ajuste de contas, optassem pela violência.

\section{Mulheres de labuta e de briga}

Em outubro de 1902, por volta das quatro horas da tarde, uma briga entre duas mulheres no Tanque da Nação chamou atenção de várias pessoas que moravam na localidade ou passavam por ali no momento do "barulho". Eustáquio Manuel Correia, trabalhador de armazém, por exemplo, passava por ali e, ao resolver "apartar" as duas mulheres, foi agredido, mas não viu por quem. Algo semelhante aconteceu com Gregório Matos, também trabalhador de armazém. Segundo ele, estava em sua casa, localizada na mesma rua, e de lá pôde escutar o "barulho", dirigindo-se então para o local com o objetivo de "apartar" as mulheres, que, por sua vez, eram suas conhecidas; mas também saiu atingido com uma facada de alguém. Essa testemunha informou ainda que o conflito atraiu muita gente desconhecida.

A contenda entre as duas mulheres ocorreu num período em que a maioria das pessoas, que trabalhavam no comércio ou como prestadoras de serviços, estava em plena atividade. Sobre isso, o interrogatório de uma das acusadas, Maria dos Anjos, conhecida por Cotá, de mais ou menos 30 anos, solteira, sapateira, analfabeta, natural e residente em Feira de Santana, é bastante elucidativo, já que, segundo ela,

Maria Eufrosina estava em disputa com uma rapariga conhecida por Senhora que vende [ilegível] em casa e que nessa ocasião Maria Eufrosina atirou uma pedra em Senhora; a pedra caiu em sua cabeça fazendo o ferimento que apresenta e vendo-se ferida ela atracou-se com Maria Eufrosina. ${ }^{21}$

20 Sobre a dificuldade para construir uma narrativa de defesa das mulheres em um processo judicial, verificar também: CORRÊA, Mariza. Morte em família: representações jurídicas de papéis sexuais. Rio de Janeiro: Graal, 1983; DAVIS, Natalie Zemon. Histórias de perdão e seus narradores na França do século XVI. São Paulo: Companhia das Letras, 2001.

21 Denúncia. A Justiça Pública por seu Promotor (Autor), Maria Eufrosina e Maria dos Anjos (Rés). Feira de 
Por meio desse depoimento, podemos ver que Maria Eufrosina diferenciavase de outras mulheres pesquisadas, pois parecia não se importar com regras de conduta como recato ou passividade. Diferentemente disso, é possível que ela pensasse em outras regras relacionadas à sobrevivência, como legitimar, frente à concorrência, um território para negociar.

O Tanque da Nação, desde o final do século XIX, constituía uma importante fonte de abastecimento de água de Feira de Santana, como observou Vicente Diocleciano Moreira. ${ }^{22}$ Esse cenário ganhou maior nitidez a partir da descrição feita por Reginilde Rodrigues Santa Bárbara, que, ao reconstituir o cotidiano das lavadeiras, revelou a dinâmica que tornou o Tanque da Nação o epicentro da movimentação da parte mais ao sul da cidade. Segundo essa autora, a presença das lavadeiras era marcante naquela região, mas ali também transitavam vários outros trabalhadores, assim como passavam muitas pessoas que iam de lá para o centro da cidade e vice-versa. ${ }^{23}$

Embora não tenhamos encontrado no processo informações sobre a ocupação de Maria Eufrosina, acreditamos que ela fosse um desses trabalhadores referidos por Santa Bárbara, possivelmente vendedora nas casas, como Senhora, ou mesmo possuidora de uma tenda no famoso Tanque da Nação, o que torna plausível pensarmos que o motivo da tensão entre as duas mulheres tivesse sido a disputa por fregueses. Outros trabalhadores também se enquadram no perfil descrito pela autora, a exemplo do ganhador Durval Pereira da Silva, que, estando a serviço de um certo Joaquim Ramos, descera até o Tanque da Nação para dar água ao seu cavalo e, por isso, estava no local no momento da briga, chegando até a tentar "apartar" as duas mulheres. ${ }^{24}$

Assim como outras mulheres aqui tratadas, Maria Eufrosina e Maria dos Anjos eram mulheres de labuta e de briga, como destacou a testemunha Durval Pereira ao afirmar que, por uns instantes, conseguira apartar as mulheres, porém logo "Maria dos Anjos veio danada com uma acha de lenha, e sem mais nem menos descarregou na cabeça de Eustachio". ${ }^{25}$ Pela ousadia e por infringirem os artigos 303 e 304 do Código Penal ao produzirem as lesões corporais nas vítimas citadas e impossibilitarem pelo menos uma delas de trabalhar por mais de 30 dias, ${ }^{26}$ elas foram condenadas. Ou seja, o arbítrio da Justiça cumpriu seu papel repressivo e, ao mesmo tempo, educativo para as demais mulheres que, como as "danadas" da vez, atreviam-se à intrepidez própria aos homens.

Diante da Justiça, outras mulheres se aproximavam entre si, seja por sua condição social de trabalhadoras, seja por também se envolverem em conflitos que se tornaram de conhecimento público. Foi o que aconteceu com Antônia Cândida do Espírito Santo, de 25 anos, solteira, lavradora, alfabetizada, natural do povoado de Tanquinho e residente no distrito de Humildes, ao denunciar que

Santana - CEDOC/UEFS. Seção Judiciária, Processos-crimes, 1903. E. 04, Cx. 100, Doc. 2104, fls. 7. v. 8.

22 MOREIRA, Diocleciano Vivente, "A agonia ocular de uma cidade cega: seca, agressões ambientais e qualidade de vida em Feira de Santana". In: Humanas, ano 02, jan.jun., p. 173-199, 2003. Apud SANTA BÁRBARA, Reginilde Rodrigues. "O caminho da autonomia na conquista da dignidade: sociabilidades e conflitos entre lavadeiras em Feira de Santana - Bahia (1929-1964)" (Dissertação de mestrado em História, Universidade Federal da Bahia, 2007), p. 74.

23 SANTA BÁRBARA, R. R. O caminho da autonomia na conquista da dignidade.

24 Denúncia. A Justiça Pública por seu Promotor (Autor), Maria Eufrosina e Maria dos Anjos (Rés). Feira de Santana - CEDOC/UEFS. Seção Judiciária, Processos-crimes, 1903. E. 04, Cx.100, Doc. 2104. fls. 15 -16.

25 Denúncia. A Justiça Pública por seu Promotor (Autor), Maria Eufrosina e Maria dos Anjos (Rés). Feira de Santana - CEDOC/UEFS. Seção Judiciária, Processos-crimes, 1903. E. 04, Cx.100, Doc. 2104. fls. 15-16.

26 Código Penal Brasileiro (Decreto n. ${ }^{\circ} 846$, de 11 de outubro de 1890) comentado por Oscar de Macedo Soares. Brasília: Senado Federal, 2004. 
foi vítima de uma "surra de palmatória na mão e nos pés". A testemunha, Pedro Alexandrino, declarou que esteve na residência da vítima, "onde a encontrou trabalhando na enxada", e, por saber que esta tinha uma rotina de labuta, atribuiu os ferimentos que a vítima apresentava ao "trabalho pesado na lavoura a qual ela se dedicava". ${ }^{27}$ Outras trabalhadoras conhecidas da vítima foram ouvidas. Leocádia de Oliveira Lopez, por exemplo, negou ter conhecimento do crime, enquanto Maria Alexandrina de Jesus disse ter ouvido da própria vítima que o motivo dos "bolos" fora o roubo que praticara na roça da família do acusado.

Assim como Antônia, que tinha uma pequena roça na qual trabalhava pesado e, por algum motivo, migrara de uma área rural de Feira de Santana para outra, várias mulheres por nós encontradas demonstraram ter escolhido mudar de região. Arcanja Maria de Jesus, nascida em São José das Itapororocas e residente no distrito de Feira de Santana, por exemplo, era lavradora, tinha uma roça e ia pessoalmente negociar com os comerciantes da cidade. ${ }^{28}$ Era nessas idas e vindas, seja de outras regiões ou dentro do município, que os sujeitos aqui tratados, ao mesmo tempo em que garantiam seu sustento e o dos seus, imprimiam suas marcas por onde passavam.

Embora as vozes das mulheres apareçam de forma reduzida em relação às dos homens nos processos analisados, tal fonte aponta indícios que nos levam a pensar que era comum entre as mulheres pobres, trabalhadoras e negras de Feira de Santana garantir a sobrevivência labutando na informalidade, espaço social que aproximava as mulheres estudadas e que também era compartilhado com outros indivíduos de seu mundo, onde muitas vezes eram forjadas estratégias fundamentais para a sobrevivência.

\section{Sociabilidades e solidariedades}

As mulheres pobres de Feira de Santana da virada do século, a despeito de serem trabalhadoras ou donas de casa, possuíam um amplo círculo de relações em que cabiam pessoas da família, vizinhos, amigos, patrões, fregueses e colegas de trabalho, sem contar os inúmeros trabalhadores com os quais, em vários momentos de seu cotidiano, elas se relacionavam. No interior desse círculo, muitas vezes, a solidariedade era a alternativa mais viável para enfrentar os desafios da vida e garantir a sobrevivência a despeito dos conflitos que também faziam parte desse cotidiano. Vejamos o exemplo de um momento de tensão entre duas mulheres.

O processo contra Maria Sabina de Jesus, de 25 anos, solteira, lavradora, analfabeta, natural e residente no distrito de Humildes, no qual ela fora acusada de assassinar Maria Patrocínia do Amor Divino enquanto esta lavava roupa numa fonte, tornou possível que as várias testemunhas chamadas para depor fornecessem à Justiça informações, tanto sobre a vida das amigas que haviam sido "criadas juntas" e eram bastante conhecidas quanto sobre a vida de outras pessoas comuns da zona rural de Feira de Santana.

De acordo com o depoimento de Felipe do Santiago, embora Maria Sabina e Maria Patrocínia nunca tivessem brigado nem sido inimigas declaradas, elas andavam diferentes por causa de Cesário, que era amasiado com ambas. Ainda

27 Denúncia. A Justiça Pública por seu Promotor (Autor), Rozendo de Oliveira Lopez Filho (Réu). Feira de Santana - CEDOC/UEFS. Seção Judiciária, Processos-crimes, 1900. E. 05, Cx. 126, Doc. 2486, fls. 14-15.

28 Denúncia. A Justiça por seu Promotor (Autor), Lidia Victoria de Macedo (Ré). Feira de Santana - CEDOC/ UEFS. Seção Judiciária, Processos-crimes, 1900. E. 02, Cx. 34, Doc. 580, fls. 78-79. 
segundo o mesmo depoente, fazia pouco tempo que elas foram vistas juntas "por ocasião de um 'corte' de Cesário onde se dera divertimento constante de sambas, comidas e bebidas que se prolongou até outro dia". ${ }^{29}$ Já Francisco Elpídio Borges destacou que "Maria Sabina era mais antiga no viver com Cesário, tanto assim que ela tem dois filhos, e com Patrocínia vivia há pouco tempo"; também declarou que Cesário "estava frequentando mais a Patrocínia e que este há pouco mais de um mês deitara uma roça dando festas em casa de Patrocínia, estando presente a Maria Sabina". ${ }^{30}$

Outro relato bastante revelador foi o depoimento de Roza Maria de São José, de 65 anos, viúva, analfabeta, natural de São Gonçalo e residente no distrito de Humildes. Segundo ela, "num dia de sexta-feira do mês passado, por volta de meio-dia, estando lavando em uma fonte situada em um terreno próximo da fazenda 'Cassano', no distrito dos Humildes, deste termo viu Sabina"31 e pediu à acusada que cortasse seu cabelo, ali mesmo, no que foi atendida; mas o processo durou menos de meia hora e, logo depois disso, Maria Sabina despediu-se dizendo que ia para casa. Dando continuidade a seu depoimento, Roza Maria disse que, cerca de três horas da tarde, quando voltou para casa, deparou-se com a filha da acusada, de apenas dois anos, aos cuidados de alguém em sua residência, e soube que esta fora deixada ali pela mãe sob a alegação de que precisava matar umas formigas e depois voltaria para buscar a menina, o que, segundo Roza Maria, só foi feito por volta das sete horas da noite, sendo que, antes de ir embora, a ré fez uns beijus em sua casa. ${ }^{32}$ Cruzando os depoimentos, depreendemos que a pessoa com quem fora deixada a criança chamava-se Loló, possivelmente filha ou neta de Roza Maria, e estas eram vizinhas de Maria Sabina.

Além do triângulo amoroso formado pelas duas mulheres e o referido amásio de ambas, a solidariedade aparece como componente fundamental na luta pela sobrevivência entre os trabalhadores do distrito de Humildes naquela época. É o caso de Cesário, que havia organizado uma "festa de corte" e "deitado uma roça", depois do que houve "samba" até de manhã: uma prática comum entre os pequenos proprietários rurais. Na época da colheita, havia uma espécie de revezamento para colher a plantação das roças da vizinhança, trabalho que só terminava quando as roças de todos os envolvidos estavam colhidas. Além do aspecto de solidariedade, tal processo também era um momento festivo, visto que o dono de cada roça, dentro de suas possibilidades, ficava responsável por providenciar comida, bebida e música para festejar o término do trabalho. Essa "relação de ajuda mútua", "troca", "dia trocado" ou "adjutório", como destaca Andréa Santos Teixeira Silva, fazia parte de uma "rede de prevenções tecidas no cotidiano rural de luta pela sobrevivência" na fração de zona rural do município de Feira de Santana, da qual fazia parte a região de Humildes. Essas formas de solidariedade, como lembra essa autora, também possibilitavam momentos de lazer, com samba de roda, versos

29 Sumário Crime. A Justiça por seu Promotor (Autor), Maria Sabina de Jesus (Ré). Feira de Santana - CEDOC/ UEFS. Seção Judiciária, Processos-crimes, 1915. E. 02, Cx. 48, Doc. 808.

30 Sumário Crime. A Justiça por seu Promotor (Autor), Maria Sabina de Jesus (Ré). Feira de Santana - CEDOC/ UEFS. Seção Judiciária, Processos-crimes, 1915. E. 02, Cx. 48, Doc. 808, fls. 18-19.

31 Sumário Crime. A Justiça por seu Promotor (Autor), Maria Sabina de Jesus (Ré). Feira de Santana - CEDOC/ UEFS. Seção Judiciária, Processos-crimes, 1915. E. 02, Cx. 48, Doc. 808.

32 O beiju constitui-se como um dos derivados da farinha de mandioca. Servia para complementar a alimentação das famílias camponesas e também era vendido na feira livre de Feira de Santana. Para uma descrição sobre o processo de plantio da mandioca e preparo da farinha e outros derivados na região de Humildes, ver: SILVA, Andréa Santos Teixeira. "Entre a casa de farinha e a estrada Bahia-Feira: experiências camponesas de conflito e sociabilidade na garantia da sobrevivência, Feira de Santana (1948-1960)" (Dissertação de mestrado em História, Universidade Federal da Bahia, 2008), p. 53-65. 
e bebidas. ${ }^{33}$ Daí a razão da referida festa mencionada por Roza Maria e outras testemunhas ter ocorrido na casa da falecida Maria Patrocínia, uma das amásias do dono da colheita.

Roza Maria, que, ao que parece, era bastante próxima de Maria Sabina, completou seu depoimento dizendo que a ré não plantava nada e que não tinha notícia de que a ré tivesse roça. Porém, mesmo que Maria Sabina tenha mentido sobre sua ocupação ao dizer-se lavradora, ela tentou construir um perfil de identificação com outras mulheres pobres e trabalhadoras e, ao mesmo tempo, se diferenciar de outras, aquelas que não tinham ocupação; no mínimo, ela demonstrou coerência com sua condição social de pobreza e com a região onde morava - a zona rural de Feira de Santana. É importante notar ainda que a ré ocupava-se de outras atividades, como a de cortar cabelo e fazer beijus. Embora não possamos afirmar que isso lhe trouxesse alguma renda, ao menos funcionava dentro da lógica de solidariedade que existia entre a população pobre da localidade e ajudava a garantir a sobrevivência uns dos outros. Nesse sentido, é sintomático o fato de Maria Sabina ter cortado o cabelo de Roza Maria e depois deixar sua filha pequena aos cuidados de Loló, ao sair para resolver algum assunto. Esse caso também nos permite observar que, no cotidiano das mulheres pobres de Feira de Santana, trabalho e informalidade caminhavam lado a lado.

Com efeito, mulheres como Maria Sabina, Maria Patrocínia, Roza Maria e Loló estavam inseridas em um contexto onde eram tecidas as redes de sociabilidades e solidariedades que eram fundamentais para a sobrevivência da população pobre de Feira de Santana. Além disso, mais de uma vez, pudemos constatar que estamos diante de mulheres que se situavam longe da submissão esperada: elas iam à luta e utilizavam laços de solidariedade para garantir sua sobrevivência e a de seus filhos, e mesmo de outros familiares.

\section{Considerações finais}

O esforço para reconstituir o passado das mulheres pobres, trabalhadoras e negras de Feira de Santana, na passagem do século XIX para o século XX, abriu-nos uma janela importante para que tivéssemos acesso ao passado de outros inúmeros personagens que faziam parte de seu cotidiano. Assim, seus familiares, amigos, vizinhos, fregueses, patrões e colegas de trabalho permearam as histórias de conflitos, sociabilidades e solidariedades nas quais nossas protagonistas estavam envolvidas.

A partir dos processos-crimes, fonte privilegiada para a reconstituição de aspectos da vida das mulheres por nós investigadas, observamos que elas eram alvos preferenciais das autoridades judiciais, que, a partir do Código Penal de 1890, ao tentar reprimi-las e discipliná-las, Ihes impunha um modelo de feminilidade oriundo da elite; isto é, pretendia-se que fossem passivas, submissas e apenas dedicadas às coisas do lar. No entanto, elas não eram ingênuas quanto às regras sociais e jurídicas e sabiam que, postas diante da Justiça, como vítimas, rés ou testemunhas, elas seriam avaliadas pelo que fizeram no passado, por seus valores e seu modo de vida. Então, cientes disso, elas acionavam o modelo de feminilidade valorizado pelas autoridades, informando o que convinha aos juízes e promotores, omitindo o que poderia lhes deixar mal-vistas. Quando o que estava em jogo eram

33 SILVA. "Entre a casa de farinha e a estrada Bahia-Feira", p. 65-78. 
os seus interesses, tais mulheres sabiam o que dizer e o que não dizer diante das autoridades judiciais.

Tais documentos ainda revelaram que, entre os pobres, era valorizado o fato de uma mulher ser chefe de família e trabalhar para garantir a própria sobrevivência e a dos seus, tanto que, para esses personagens, esses requisitos poderiam conferir respeitabilidade às mulheres pobres e trabalhadoras.

No mundo de nossas protagonistas, também havia momentos de conflitos que, por vezes, eram resolvidos de forma violenta. Muitas dessas mulheres, longe da passividade considerada própria a elas, também podiam ser provocativas e agressivas e se envolver em conflitos diretos.

As mulheres pobres, trabalhadoras e negras de Feira de Santana transitavam entre o público e o privado com desenvoltura e tinham uma ampla rede de relações. Os laços de sociabilidade e de solidariedade construídos por elas incluíam familiares, a vizinhança, fregueses e outros inúmeros trabalhadores rurais e urbanos de Feira de Santana, constituindo aspecto fundamental na luta pela sobrevivência.

Em suma, esperamos que este estudo contribua para o conhecimento sobre as mulheres pobres, trabalhadoras e negras de Feira de Santana, assim como para a investigação sobre o passado dos outros sujeitos sociais que faziam parte de seu mundo; e desperte o interesse de outros pesquisadores para o desafio de enfrentar os vários silêncios existentes em torno do passado dessas mulheres, além de servir de instrumento na (re)construção e afirmação da autoestima das crianças pobres, muitas das quais trabalhadoras e negras, que poderão ver a experiência de mulheres como sua mãe, avó ou vizinha reverenciada pela historiografia.

Recebido em 16/07/2016 Aprovado em 31/12/2016 
